\title{
INVESTIGANDO REPRESENTAÇÕES IDENTITÁRIAS EM CHARGES NO CONTEXTO DE SALA DE AULA: MULTIMODALIDADE, LEITURA CRÍTICA E INTERSECCIONALIDADE
}

\author{
INVESTIGATING IDENTITY REPRESENTATIONS IN CARTOONS IN THE \\ CLASSROOM CONTEXT: MULTIMODALITY, CRITICAL READING AND \\ INTERSECTIONALITY
}

\author{
José Maria de Aguiar Sarinho Júnior \\ Universidade Federal da Paraíba, João Pessoa, Paraíba, Brasil \\ jaguiarsarinho@yahoo.com.br \\ Fábio Alexandre Silva Bezerra \\ Universidade Federal da Paraíba, João Pessoa, Paraíba, Brasil \\ fabes10@yahoo.com.br
}

Resumo: No contexto de mudanças significativas na compreensão acerca do texto, bem como dos processos de leitura e de escrita, na sociedade contemporânea, este artigo tem como objetivo principal discutir representações identitárias construídas por meio do texto multimodal charge no contexto de sala de aula na Educação Básica. Para tanto, utilizamos conceitos e categorias de análise propostos por Kress e van Leeuwen (2006) em sua Gramática do Design Visual, bem como aprofundamos as discussões com base em estudos identitários (MOITA LOPES, 2006; ANDRADE, 2014) a partir de uma perspectiva descolonial (KLEIMAN, 2013; SANTOS, 2004). Este estudo, caracterizado como pesquisa-ação de abordagem qualitativa e interpretativa, foi desenvolvido em escola pública estadual da cidade de Orobó, com alunos/as dos $2 .^{\circ}$ e $3 .^{\circ}$ anos do Ensino Médio. Os resultados apontam para a necessidade do desenvolvimento de práticas de leitura e de escrita baseadas em uma abordagem crítica e interseccional, que integrem múltiplas linguagens e semioses em sala de aula, além de incluir discussões sobre questões sociais complexas, como as experiências identitárias, em um país com características tão diversas em face a frequentes mudanças na vida sociocultural, histórica e política.

Palavras-chave: Multimodalidade; Charge; Representações Identitárias; Ensino

Abstract: In the context of significant changes in the understanding about texts, as well as the reading and writing processes, in contemporary society, this article aims mainly at discussing identity representations constructed through the multimodal text cartoon in the classroom context in regular schools. For this purpose, we use concepts and categories of analysis proposed by Kress and van Leeuwen (2006) in their Grammar of Visual Design, and also expand the discussions based on identity studies (MOITA LOPES, 2006; ANDRADE, 2014) from a decolonial perspective (KLEIMAN, 2013; SANTOS, 2004). As an action research with a qualitative and interpretative approach, this study was developed in a state public school in the city of Orobó, with students from the 2nd and 3rd years of high school. The results point to the need to develop reading and writing practices based on a critical and intersectional approach, which integrate multiple languages and semioses in the classroom, in addition to

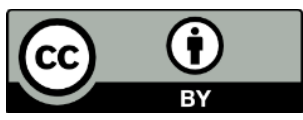


including discussions on complex social issues, such as identity experiences, in a country with such diverse characteristics in the face of frequent changes in sociocultural, historical and political life.

Keywords: Multimodality; Cartoon; Identity Representations; Teaching

\section{INTRODUÇÃO}

Os estudos que levam em conta o código semiótico verbo-visual (BEZERRA, 2016; HALLIDAY, 1994; HEBERLE, 2012; KRESS; VAN LEEUWEN, 2006), dentre outros, compartilham uma visão de linguagem na qual os significados construídos por meio dos diversos gêneros textuais são obtidos a partir do diálogo entre sistemas semióticos diversificados, em uma perspectiva multissensorial e multidimensional.

Tal visão mais ampla sobre configurações textuais na contemporaneidade assume destacada relevância quando consideramos que abordagens linguístico-discursivas multissemióticas podem nos levar a compreensões mais avançadas acerca das diversas reconfigurações da vida sociocultural, com vistas ao pleno desenvolvimento do respeito e da tolerância pela heterogeneidade, pelas minorias sociais e pelos grupos marginalizados, por exemplo.

Nessa perspectiva, a Linguística Aplicada (LA), em produtivo diálogo com construtos teóricos e metodológicos da Análise Crítica do Discurso (ACD), como área de estudos eminentemente multidisciplinar, possibilita-nos demonstrar que os diversos discursos presentes nas relações em sociedade são construções não apenas linguísticas, mas também socioculturais e históricas. Com base na multiplicidade de aspectos da vida social que a LA toma como cerne de sua própria construção do conhecimento, podemos evidenciar o contexto de ensino e aprendizagem em grande parte das escolas de Educação Básica em âmbito nacional.

Nesse contexto, vale ressaltar a concepção acerca de multimodalidade e multiletramentos, cujas ideias estão vinculadas tanto à presença marcante das tecnologias da comunicação e da informação nas interações, quanto ao fortalecimento da leitura crítica de fatos vividos na sociedade. Dessa forma, a Gramática do Design Visual (KRESS; VAN LEEUWEN, [1996] 2006), doravante GDV, elaborada a partir da Linguística Sistêmico-Funcional (HALLIDAY, 1994), doravante LSF, tem sido referendada como aparato teórico de análise do uso das linguagens em suas multiplicidades através de práticas de letramento.

A fim de demonstrar a relevância de desenvolvermos práticas de multiletramentos ${ }^{1}$ no contexto escolar, objetivamos discutir representações identitárias de homossexuais, idosos, negros e mulheres construídas por meio do texto multimodal charge, entre adolescentes que cursam o Ensino Médio em uma escola pública do estado de Pernambuco. Devido ao fato de que tais representações não costumam compor preocupações centrais em nossa sociedade (MOITA LOPES, 2006, 2013), acreditamos ser importante criar espaços para que os/as alunos/as possam desenvolver posicionamentos crítico-reflexivos sobre tais questões. Como objetivos específicos, buscamos (i) compreender a relevância de práticas pedagógicas com base nos multiletramentos durante o trabalho de leitura e produção textuais em sala de aula; além de (ii) propor estratégias de estudo da charge como práticas textual e sociodiscursiva, contribuindo com o debate sobre a relevância da multimodalidade na atualidade.

Com vistas ao desenvolvimento dessa discussão, nosso estudo está estruturado conforme as seguintes seções: fundamentação teórica, na qual são apresentados os principais

\footnotetext{
${ }^{1}$ Tomamos aqui o conceito de multiletramentos descrito por Rojo (2012, p. 13), a partir do que foi proposto pelo New London Group (2000 [1996]), que "aponta para dois tipos específicos e importantes de multiplicidade presentes em nossas sociedades, [...], na contemporaneidade: a multiplicidade cultural das populações e a multiplicidade semiótica de constituição dos textos por meio dos quais ela se informa e se comunica".
} 
conceitos relacionados aos multiletramentos e aos nossos campos de estudo, a saber ACD, GDV, LA e LSF; metodologia de pesquisa, em que são desenvolvidas as categorias relacionadas aos procedimentos metodológicos utilizados ao longo do trabalho; análise do corpus, na qual é possível relacionar a teoria apresentada com a prática; e as considerações finais.

\section{MULTILETRAMENTOS: AMPLIANDO VISÕES DE MUNDO A PARTIR DA DIVERSIDADE DE RECURSOS SEMIÓTICOS}

Devido às grandes mudanças ocorridas nas últimas décadas, a internet e a globalização, principalmente, têm possibilitado múltiplas maneiras de produção, circulação e recepção das informações. Segundo Bezerra (2016, p. 196), "somos demandados diariamente para lidar com textos multimodais, quer seja na rua, em casa, no clube, nos restaurantes, [...], e em inúmeros outros contextos em que práticas de letramento diversas são exigidas"; sendo assim, percebese que a escola deve sempre assegurar as inúmeras e variadas práticas sociais que fazem uso da leitura, da escrita e, primordialmente, da imagem.

Com vistas à apreensão das diversas dimensões presentes em um texto, são solicitadas do interlocutor "não somente habilidades e competências referentes a aspectos linguísticos, mas também a considerações socioculturais e significações multimodais" (HEBERLE, 2012, p. 83), por se tratar, evidentemente, de um texto multissemiótico. Ora, não faz parte da vivência e da comunicação entre os/as nossos/as alunos/as o uso de diversos modos e recursos semióticos?

Nessa perspectiva, torna-se urgente, conforme Bezerra (2016, p. 196) defende, "que se incluam nos contextos escolares práticas letradas que ultrapassem a modalidade escrita e o livro impresso como material de referência". Deste modo, constitui-se como tarefa do/da professor/a mediador/a não só propiciar a atualização dos conhecimentos prévios por meio do código semiótico verbal, mas também atribuir ênfase às imagens.

Partindo do pressuposto de que "toda prática discursiva [...] é uma forma de prática social" (MEURER, 2005, p. 94), a charge, geralmente, é bem marcada por questões reflexivas acerca do poder; nesse caso, o humor deriva da transgressão dessas imposições de poder. Além disso, convém chamar a atenção dos/as alunos/as para a questão da hegemonia que, de acordo com Meurer (2005, p. 102), diz respeito à "continuidade do exercício de poder de uns sobre os outros". Nesse sentido, é interessante ao/à professor/a suscitar uma reflexão acerca de quem, geralmente, ocupa alguns cargos e espaços, tais como: gerência de banco ou de grandes empresas, shoppings, dentre outros.

A respeito disso, abre-se uma discussão acerca das vozes do Sul, metáfora utilizada por Boaventura de Sousa Santos (2004) para referir-se àqueles indivíduos marginalizados e tão silenciados em nossa sociedade. Torna-se muito útil, então, disseminar entre os/as alunos/as a necessidade de se questionar essas hegemonias, a partir de situações problematizadoras propostas pelo/a professor/a.

Dessa forma, acreditamos que é possível uma reconfiguração do ambiente escolar, com vistas a uma utilização mais democrática do mesmo e a um trabalho de ensino e aprendizagem mais eficaz a partir da "pedagogia dos multiletramentos", conforme propõe Rojo (2012). Tal experiência tem como base o manifesto do Grupo de Nova Londres, cuja proposta A Pedagogy of Multiliteracies - Designing Social Futures (1996) tinha por intenção fazer com que a escola se apropriasse dos novos letramentos emergentes na sociedade contemporânea a fim de incluir o trabalho não apenas com múltiplas semioses mas também múltiplas culturas, refletindo, assim, a realidade de alunos/as no contexto contemporâneo. 
Corroborando as ideias apresentadas acima, Nascimento, Bezerra e Heberle (2011) pontuam a necessidade de expansão do trabalho com textos multimodais na sala de aula, porque, só assim, haverá "o desenvolvimento de uma consciência crítica sobre como imagens e linguagem verbal são ferramentas poderosas de significação e de construção da realidade" (p. 547), combatendo, deste modo, a escola elitista, e estimulando experiências que prezem por novas e múltiplas práticas socioculturais.

\section{CONTRIBUIÇÕES PARA UMA PERSPECTIVA SOCIODISCURSIVA E MULTISSEMIÓTICA DE USO DA LÍNGUA}

O campo de estudo e investigação da Linguística Aplicada é amplo, interdisciplinar e se estabelece a partir de relevantes práticas sociais que são envolvidas pela linguagem em seus mais diversos suportes, mídias e contextos. Nessa perspectiva, percebem-se entre a LA e as ciências sociais e humanas fortes elos e produtivos diálogos com vistas a investigar e buscar novos conhecimentos em diferentes contextos discursivos que forneçam possibilidades de reflexão e caminhos para a práxis sobre questões complexas da vida em sociedade, objetivando, acima de tudo, "reinventar a vida social, [...] uma vez que a pesquisa é um modo de construir a vida social ao tentar entendê-la" (MOITA LOPES, 2006, p. 85).

Nesse contexto, é importante que se atribua uma atenção à questão da necessidade de reorganização da vida social a partir, principalmente, das propostas de "suleamento" e de "descolonialidade" (KLEIMAN, 2013). Ora, se são criadas possibilidades para que aqueles que estão à margem da sociedade sejam ouvidos, suas práticas de letramentos deverão ser levadas em consideração em relação ao uso da linguagem e ao exercício pleno da cidadania. Além disso, partindo do pressuposto de que a linguagem produz efeitos de sentidos e está envolvida por atividades sociais, é esperado que questões de cunho ideológico, cultural, histórico, econômico, político, dentre outras que envolvem dominações hierárquicas, emancipações se façam presentes.

Nesse sentido, Fairclough e Wodak (1997) consideram a linguagem como mantenedora e/ou transformadora das relações existentes de poder. Halliday (1994), por sua vez, defende que a análise do discurso deve estar atrelada às situações sociais, de uma maneira culturalmente situada. Também nesse sentido, Kress e van Leeuwen (2006) contribuem para a descrição e o entendimento mais aprofundado do potencial semiótico de textos multimodais à medida que destacam a grande importância sociocultural e histórica que têm tido as imagens e outros recursos semióticos na produção dos diferentes gêneros na atualidade. Percebemos, assim, que a LA, a ACD, a LSF e a GDV dialogam muito bem, não só porque essas abordagens teóricas possibilitam distintas ambiências de análise, mas também porque cada uma delas pode proporcionar uma melhor compreensão dessa complexidade, uma vez que tanto a análise de texto quanto sua produção devem acontecer com base nas várias modalidades multissemióticas, cujas preocupações estão voltadas para o contexto com foco em questões complexas com impactos diferentes para nossa vida em sociedade. Vale frisar, ainda, que a LA apresenta em seu cerne uma característica "transdisciplinar de produção do conhecimento" (MOITA LOPES, 2006, p. 97), o que acentua sua relação com a ACD, a multimodalidade, e com a LSF, cuja concepção de língua se desenvolve como um sistema de escolhas lexicais, gramaticais e discursivas, a partir de considerações sobre os contextos de situação mais específicos e acerca do contexto de cultura mais amplo. Se a realidade é construída socialmente através do uso da linguagem, deve ser nosso compromisso desafiar e transformar discursos que perpetuam estruturas de dominação em nossa sociedade.

A ACD percebe o gênero textual como uma prática social, pois "ocorre em determinado contexto e envolve diferentes agentes que o produzem e consomem" (MEURER, 
2005, p. 82), utilizando-se de perspectivas descritivo-interpretativa e explicativa. Para isso, três dimensões são essenciais (MEURER, 2005): (i) a textual, em que são percebidos "aspectos relevantes do léxico, das opções gramaticais, da coesão ou da estrutura do texto" (p. 83); (ii) a discursiva, através da qual "se estabelece a coerência do texto, qual é a sua força ilocucionária e que aspectos intertextuais e interdiscursivos estão presentes no texto" (p. 83); (iii) a social, com vistas a explicar "como as estruturas sociais moldam e determinam os textos" (p. 83). Aliada a essa vertente teórica, a LSF também é utilizada como "potencial de significados à disposição dos falantes", conforme Fuzer e Cabral (2014, p. 13) pontuam, intencionando "estabelecer relações, representar o mundo e, com isso, satisfazer determinadas necessidades em contextos sociais específicos" (FUZER; CABRAL, 2014, p. 13).

Outrossim, Kress e van Leeuwen (2006), a partir dos estudos do código verbal elucidados por Halliday (1994), propuseram um estudo dos signos linguísticos não-verbais com vistas à descrição dos diversos modos com os quais as imagens, por exemplo, constroem representações da realidade, estabelecem relações e criam composições textuais.

Nesse contexto, a GDV (KRESS; VAN LEEUWEN, 2006) constitui um mecanismo de análise crítico-reflexiva das imagens com base na semiótica social. Essa gramática apresenta-se estruturada a partir de três metafunções: a primeira, de cunho representacional, diz respeito à forma como os participantes estabelecem relações entre si, quer sejam baseadas em representações narrativas ou conceituais. No que diz respeito à segunda metafunção, a interação extrapola a composição imagética para estabelecer diálogo com o interlocutor, promovendo uma relação entre o participante representado e o participante interativo, levando em conta o contato estabelecido, a distância social entre eles, a perspectiva do ângulo da representação, além do valor de realidade expresso por tal representação visual. Por último, a composicional evidencia a forma como os elementos da composição se inter-relacionam em busca da integração dos componentes visuais e interativos, utilizando-se do valor de informação, da saliência e da estruturação.

A seguir, são traçados os procedimentos metodológicos como parte integrante deste trabalho, e a análise do corpus, que une as concepções elencadas às práticas efetivas de trabalho com charges, as quais se apresentam, neste trabalho, a partir de um estilo estático e estão veiculadas em meio eletrônico.

\section{PROCEDIMENTOS METODOLÓGICOS}

A relevância desse estudo reside numa proposta com vistas a uma maior inserção dos textos multimodais em sala de aula, a partir das práticas de leitura e de escrita. Ademais, a metodologia que embasa este trabalho é de pesquisa-ação, o que possibilita uma abordagem investigativa em ensino e aprendizagem do gênero textual multimodal charge.

Para esta pesquisa, foram desenvolvidas as seguintes atividades: 1) foi solicitada para os/as alunos/as uma primeira produção verbal de análise das charges previamente selecionadas, as quais envolvem minorias, tais como: homossexuais ${ }^{2}$, idosos $^{3}$, negros $^{4}$ e mulheres $^{5} ; 2$ ) em seguida, foram desenvolvidas oficinas de maneira lúdica e sob o enfoque dos multiletramentos e da GDV; 3 ) por fim, os/as alunos/as foram convidados/as a produzirem charges, através das

\footnotetext{
${ }^{2}$ Disponível em: http://www.tribunadainternet.com.br/charge-do-duke-1478/ . Acesso em: 17 jun. 2019.

${ }^{3}$ Disponível em: http://chargedodiemer.blogspot.com/2013/01/chargeviolencia-contra-idosos.html . Acesso em: 17 jun. 2019

4 Disponível em: https://ponte.org/charge-negros-sao-as-maiores-vitimas-da-violencia/ . Acesso em: 17 jun. 2019.

${ }^{5}$ Disponível em: http://chargesprotestantes.blogspot.com/2008/02/violncia-domstica.html . Acesso em: 17 jun. 2019.
} 
quais fossem exploradas as novas concepções acerca dos temas desenvolvidos em sala de aula, enfatizando variados recursos semióticos (letramento visual ${ }^{6}$ ) e diferentes discursos de cunho sociopolítico, histórico e cultural (letramento crítico-reflexivo).

Mais especificamente, no tocante ao foco na análise do texto multimodal a partir dos conceitos e categorias de análise da GDV, foram feitas escolhas adicionais para nossa análise. Quanto à metafunção representacional, foi dado destaque para as representações narrativas. Sobre a metafunção interativa, exploramos os recursos de contato e de distância social. Por fim, da metafunção composicional, optamos por focar no sistema do valor de informação.

A seguir, por meio da Tabela 1, elencamos as atividades desenvolvidas durante as oficinas:

Tabela 1 - Atividades e oficinas desenvolvidas

\begin{tabular}{|c|c|c|}
\hline Atividades & Tempo & Descrição \\
\hline Oficina 1 & 50 min. & $\begin{array}{l}\text { Discussão sobre charges previamente selecionadas e análise verbal } \\
\text { das mesmas, as quais estão referenciadas no início desta seção, em } \\
\text { nota de rodapé. }\end{array}$ \\
\hline Oficina 2 & $50 \mathrm{~min}$. & $\begin{array}{l}\text { Jogo do Verdadeiro ou Falso, cujos objetivos foram refletir acerca } \\
\text { dos textos oficiais e promover a integração entre os participantes. } \\
\text { Textos-base: Artigo } 3^{\circ} \text {, inciso XLI, e Artigo } 5^{\circ} \text {, inciso XLI, da } \\
\text { Constituição Federal, } 1988 \text {. }\end{array}$ \\
\hline Oficina 3 & $50 \mathrm{~min}$. & $\begin{array}{l}\text { Textos-base: Lei } .^{\circ} 10.741 \text {, de } 1^{\circ} \text { de out. de } 2003 \text {; Lei n. } 11.340 \text {, de } \\
07 \text { de agosto de } 2006 \text {. }\end{array}$ \\
\hline Oficina 4 & $50 \mathrm{~min}$. & $\begin{array}{l}\text { Jogo do Passa ou Repassa, cujo objetivo foi debater sobre Mitos e } \\
\text { Verdades acerca dos seguintes temas: } \\
\text { Homossexualidade não tem cura, homofobia sim. Disponível em: }< \\
\text { https://www.brasildefato.com.br/2017/09/21/artigo-or- } \\
\text { homossexualidade-nao-tem-cura-homofobia-sim/>. Acesso em: } 30 \\
\text { jun. } 2019 \\
\text { O racismo reforça a violência que existe no Brasil. Disponível em: }< \\
\text { http://www.vozdascomunidades.com.br/geral/opiniao-o-racismo- } \\
\text { reforca-violencia-que-existe-no-brasil/>. Acesso em: } 30 \text { jun. } 2019\end{array}$ \\
\hline Oficina 5 & $50 \mathrm{~min}$. & $\begin{array}{l}\text { Os idosos estão sendo descartados. Disponível em: }< \\
\text { https://www.gazetadopovo.com.br/opiniao/artigos/os-idosos-estao- } \\
\text { sendo-descartados-ejkx5kseg6ybc6avbrff200vb/>. Acesso em: } 30 \\
\text { jun. } 2019 \\
\text { A violência contra a mulher e o silêncio da sociedade. Disponível em: } \\
<\quad \text { https://www.gazetadopovo.com.br/opiniao/artigos/a-violencia- } \\
\text { contra-a-mulher-e-o-silencio-da-sociedade- } \\
\text { ci8jae720igbchw2er9g5gm2w/>. Acesso em: } 30 \text { jun. } 2019\end{array}$ \\
\hline
\end{tabular}

Oficina 650 min. Produção de charges com foco nas Metafunções Representacional, Interativa e Composicional (KRESS; van LEEUWEN, 2006).

Fonte: elaborado pelos autores.

O trabalho foi desenvolvido em uma escola pública estadual da cidade de Orobó, região do Agreste pernambucano, com alunos/as do $2 .^{\circ}$ e $3 .^{\circ}$ anos do Ensino Médio. Torna-se

\footnotetext{
${ }^{6}$ Tomamos aqui o conceito de letramento visual proposto por Serafini (2014, p. 23, tradução nossa), como sendo um "processo de produção de significados em operação com disposições multimodais, [...], a partir de uma variedade de perspectivas que considerem os requisitos de contextos sociais particulares".
} 
importante destacar que tal escola faz parte da rede de Escolas Integrais do Estado de Pernambuco, recebendo a designação de EREM (Escola de Referência em Ensino Médio). Atualmente, essa instituição de ensino é composta por 336 alunos/as, que, em sua grande maioria, possuem pais agricultores e pouco escolarizados, e que procedem de áreas rurais do município.

Nosso corpus é composto de noventa produções, que foram realizadas por 15 alunos/as, com idades entre 16 e 17 anos, os quais foram selecionados devido a sua presença no contraturno do horário regular de aulas.

\section{IMPLICAÇÕES DA MULTIMODALIDADE E DOS MULTILETRAMENTOS EM LEITURA E PRODUÇÃO DE TEXTOS}

As discussões sobre homofobia, violência contra idosos e mulheres e preconceito racial estão na "ordem do dia" das escolas. Assim, é adequado não somente informar sobre, mas também proporcionar debates acerca dos preconceitos e da violência que rondam a sociedade, com vistas a um maior distanciamento e um melhor enfrentamento desses estereótipos. Ora, não deve ser a sala de aula um espaço de discussão sobre questionamentos diversos, incertezas e ambivalências, visando à construção de opiniões próprias e de valores democráticos e pluralistas?

Dessa forma, os/as professores/as no papel de mediadores/as devem problematizar, em sala, o respeito por cada um, pois busca-se uma sociedade mais acolhedora das diversidades, marcadamente as identitárias (MOITA LOPES, 2013). Isto é, torna-se urgente o reconhecimento das instabilidades contemporâneas, no intuito de "queerizar [...] qualquer visão universalista, trans-histórica e transcultural dos gêneros, das sexualidades e das raças" (MOITA LOPES, 2013, p. 244). Quem sabe, dessa maneira, narrativas como o Texto 1, destacado abaixo, que enfatizam a relação homossexual como algo inaceitável, possam tomar novos contornos em um futuro próximo. Vale frisar, contudo, que o texto fora produzido na Oficina 1, antes dos debates e da realização das atividades propostas nesta pesquisa.

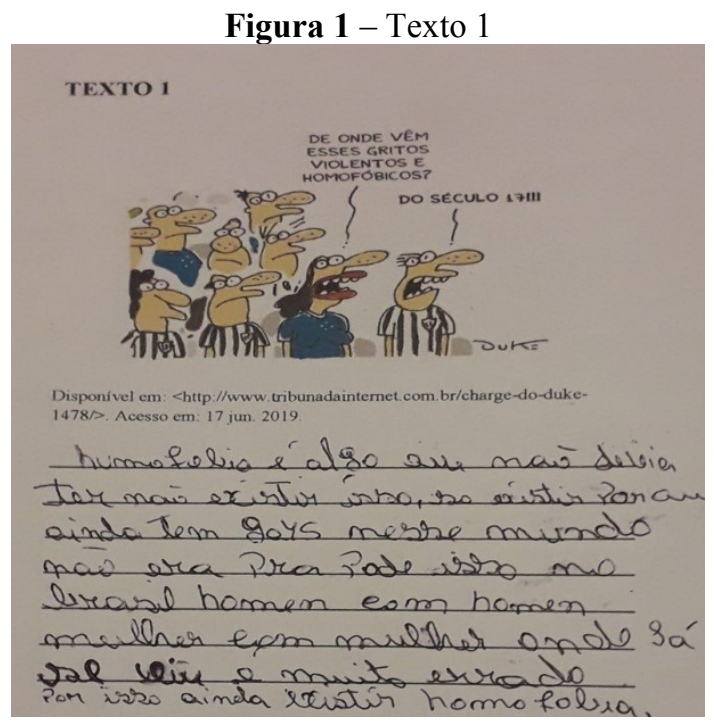

Fonte: produzido pelos/as alunos/as participantes.

Outro exemplo de representação identitária objeto de diversos preconceitos em nossa sociedade diz respeito aos idosos. Nesse sentido, torna-se válido "observar o modo como são construídos certos gestos de interpretação sobre a velhice” (ANDRADE, 2014, p. 139). A partir 
da argumentação do Texto 2, a seguir, pode-se perceber que a questão da velhice transita em um continuum que vai desde a manipulação do imaginário sobre o idoso até a referência a alguém extemporâneo. Tal postura confirma que não há "uma possibilidade de se dizer ou de ser dito [...] de outra forma que não aquela que é compartilhada pelo senso comum" (ANDRADE, 2014, p. 160).

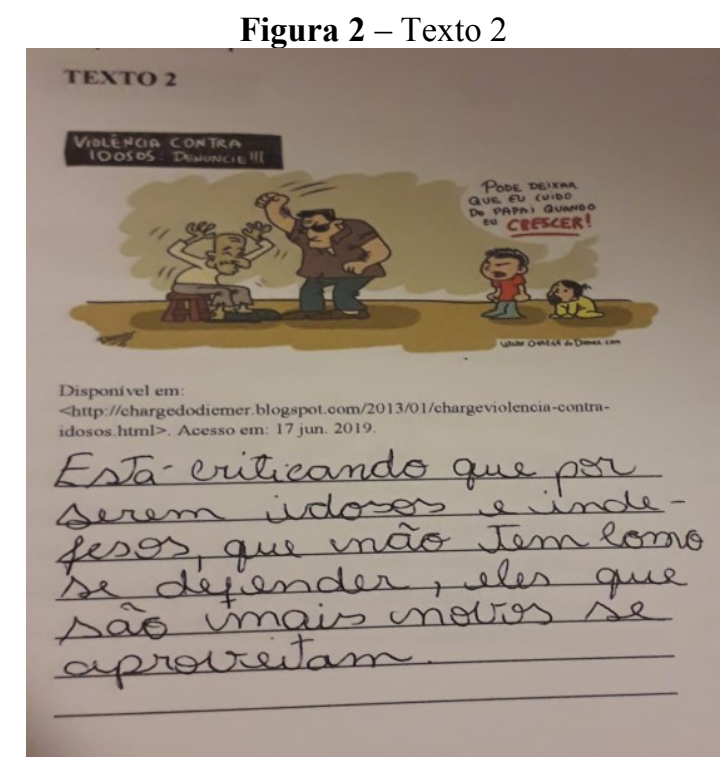

Fonte: produzido pelos/as alunos/as participantes.

Sendo assim, a proposta de uma LA do emergente (MOITA LOPES, 2013) propõe direcionar uma atenção mais complexa e de cunho político para as questões de gênero e sexualidade, de raça, do idoso, dentre outras, as quais podem se revelar "alternativas para nosso presente" e, consequentemente, "decisivas para uma vida social mais justa e ética" (MOITA LOPES, 2013, p. 233), conforme relatos presentes nos Textos 3 e 4, reproduzidos em seguida:

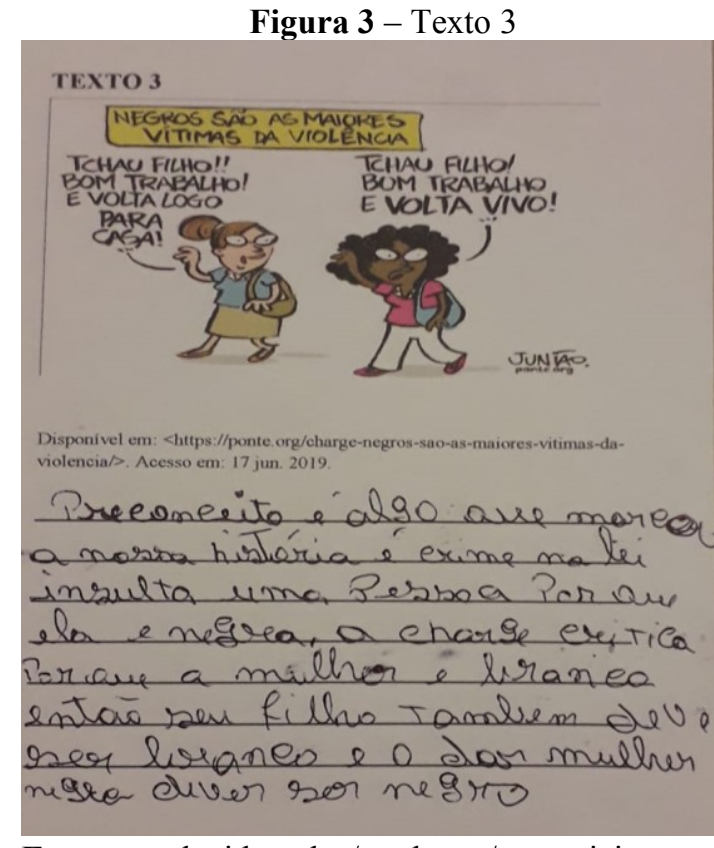

Fonte: produzido pelos/as alunos/as participantes.
Figura 4 - Texto 4

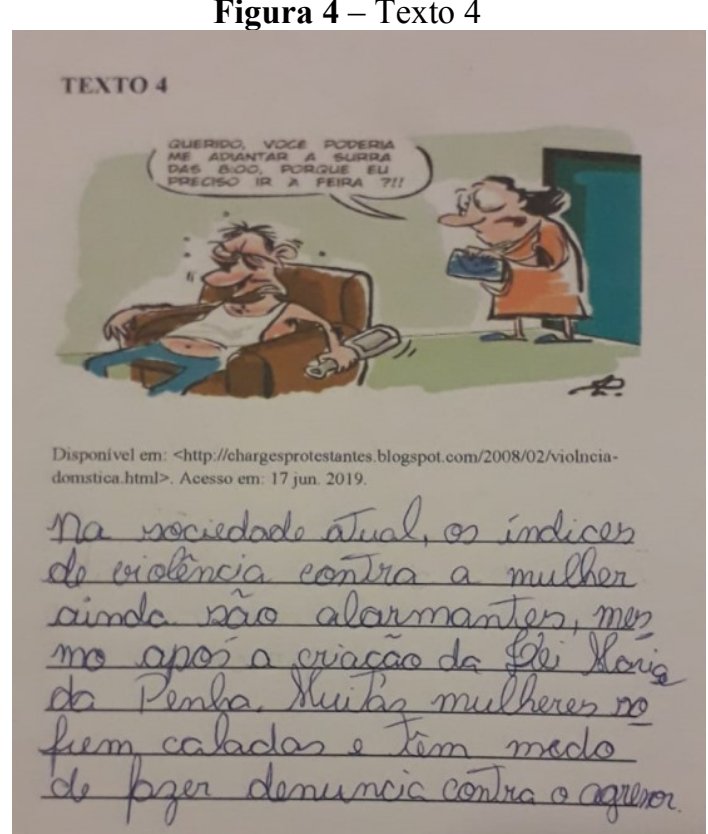

Fonte: produzido pelos/as alunos/as participantes. 
Com base nessa ideia, convém fazer referência à Constituição Federal, de 1988; à Lei n. ${ }^{\circ} 10.741$, de $1 .^{\circ}$ de outubro de 2003; e à Lei n. ${ }^{\circ} 11.340$, de 07 de agosto de 2006 que dispõem sobre normas e diretrizes para a formulação e execução de políticas públicas e serviços destinados a essas minorias. É importante frisar que tais legislações têm, paulatinamente, obtido efeitos positivos na (re)construção do imaginário e das identidades acerca das situações de vulnerabilidade elencadas acima em nosso país.

Torna-se imprescindível, portanto, um investimento mais amplo em pesquisas, porque, só assim, "os desafios inerentes às mudanças sócio-históricas e linguísticas que experimentamos atualmente" (MOITA LOPES, 2013, p. 229) poderão interferir na realidade com vistas a transformá-la. Assim, cabe, principalmente, à escola e aos/às educadores/as polemizar discursos e posições hegemônicos de nossa sociedade, a fim de difundir "a importância de pensar outras sociabilidades para a vida social", conforme Moita Lopes (2006, p. 104) ratifica.

\section{APRESENTAÇÃO E DISCUSSÃO DOS RESULTADOS: UMA PROPOSTA DE TRABALHO COM O GÊNERO CHARGE COM BASE EM REPRESENTAÇÕES IDENTITÁRIAS}

Há mais de duas décadas, os PCNs, por meio dos Temas Transversais, são enfáticos em defender que "o grande desafio da escola é reconhecer a diversidade como parte inseparável da identidade nacional" (BRASIL, 1998, p. 117). Nessa perspectiva, devemos compreender que o ambiente escolar pode ser visto e vivenciado como contexto privilegiado para que preconceitos e velhos estereótipos adquiram outras configurações no sentido do desenvolvimento de posturas mais inclusivas na sociedade. Abaixo, analisamos produções realizadas pelos/as alunos/as participantes da pesquisa.

Acreditamos que a aprendizagem acontece significativamente por meio da produção e da leitura de textos, ora estabelecendo relações entre o acervo pessoal e o gênero, ora questionando o conhecimento com a intenção de alterá-lo, formando estudantes leitores/as e produtores/as autônomos/as capazes de lidar, principalmente, com a questão da criticidade tão peculiar à charge, e sua relevância em relação aos multiletramentos.

O Texto 5, a seguir, consegue demonstrar o poder que as imagens têm de comunicar fatos e aspectos das relações sociais. Aqui, destacamos a relevância do trabalho desenvolvido em sala de aula durante a Oficina 6. A partir de uma análise composicional, com base na GDV, observa-se que o/a discente distribuiu os elementos (Constituição Federal e pessoa integrante do movimento LGBTQI+) na posição real da imagem, intentando atribuir-lhe um ar de concretude e de verdade. O signo verbal pride (orgulho), escrito na roupa, reitera uma força ilocucionária de luta, de resistência e de (re)existência, evidenciada através das vestimentas utilizadas e do movimento realizado pelo opressor.

Nesse contexto, em consonância com Kress e van Leeuwen (2006), concordamos que "as mensagens produzidas [...] vão refletir as diferenças, incongruências e confrontos que caracterizam a vida social” (p. 20, tradução nossa). Na composição imagética, observa-se o Congresso Nacional que ocupa a posição de menor valoração (ideal, parte superior), além da coloração atípica do céu, reforçando a mensagem de não atuação e de omissão do Legislativo diante de diversas situações, provocando possíveis condições de desamparo e perigo. Isso proporcionou, portanto, a intervenção imediata do Supremo, conforme foi demonstrado por meio do texto verbal, uma vez que a discriminação homofóbica/transfóbica tem permanecido sem nenhum tipo de apreciação e de aprovação de leis específicas em nosso país. 
Figura 5 - Texto 5

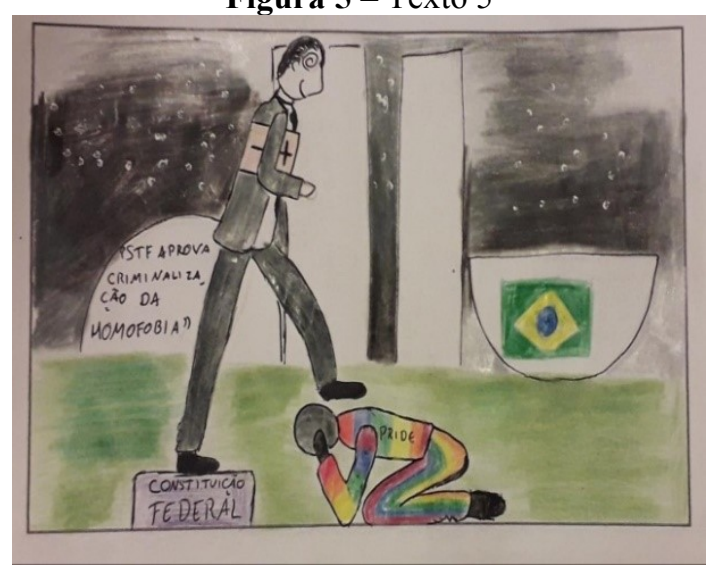

Fonte: Produzido pelos/as alunos/as participantes.

Assim, ratificamos que as imagens utilizadas são fortes e estabelecem não só um convite à reflexão, mas também suscitam um engajamento contra tais problemáticas, concordando, portanto, com Rojo $(2012$, p. 11) que, certamente, há lugar na escola para o plurilinguismo, para a multissemiose e para uma abordagem pluralista das culturas. Dessa forma, a práxis da sala de aula estabeleceu um diálogo crítico com a realidade, tornando-se possível transformar ou modificar velhas ideologias e criando "inteligibilidade sobre problemas sociais em que a linguagem tem um papel central” (MOITA LOPES, 2006, p. 14).

A seguir, expomos o Texto 6 , o qual é um protótipo de que os significados do texto são construídos por uma multimodalidade sociossemiótica referendada por Kress e van Leeuwen (2006, p. 16, tradução nossa), de que "a escrita e a imagem estão em uma relação cada vez mais instável". Tomando por base a presença de vetores, percebemos a ênfase dada pelo/a produtor/a do texto à representação narrativa e seu respectivo vetor: na perspectiva do ator (homem) em relação a sua meta (mulher). Em relação à fala, presente no balão, há outro vetor no instante em que o dizente (mulher) conecta-se ao conteúdo ("O MEU AMOR É MAIS FORTE"). A verdade é que não conseguimos escapar da imagem forte do braço lançado em posição de luta, o qual se sobressai, levando à reflexão de que as marcas da violência causadas na mulher não são consequência apenas da agressão física, mas também da fúria proferida verbalmente.

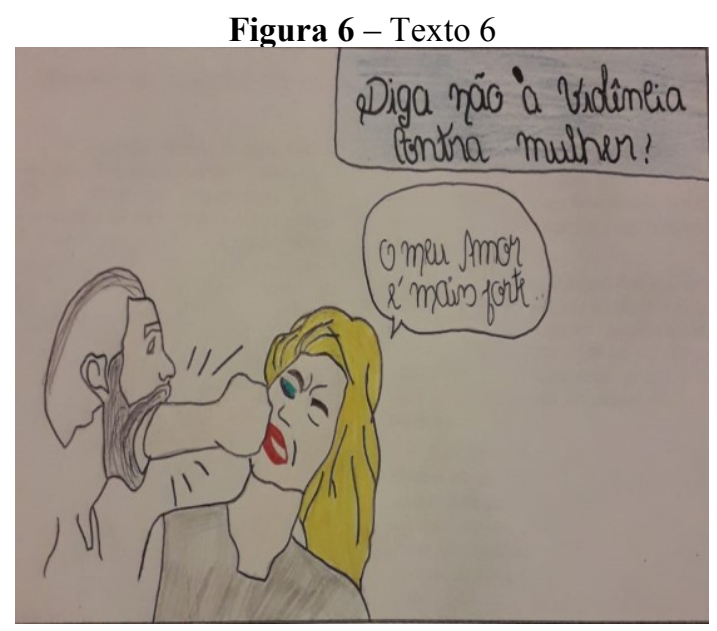

Fonte: Produzido pelos/as alunos/as participantes. 
Tendo em vista a produção acima, notamos que há "a necessidade de se ampliar o próprio conceito de linguagem em sala de aula para incluir recursos semióticos que vão além da palavra escrita" (BEZERRA, 2016, p. 201). Isto é, estamos diante de um campo diversificado e bastante amplo de estudos, pesquisas e investigação: o texto multimodal.

As duas produções textuais seguintes, Textos 7 e 8 , dialogam, à medida que retratam a "preocupação com novas epistemes" (MOITA LOPES, 2006, p. 88), representadas pela criança negra e pelo idoso. Em ambas as charges, evidencia-se "o ideal de reinventar a emancipação social" (p. 102): na primeira, através dos estudos; na segunda, por meio da conscientização acerca da exploração socioeconômica praticada contra o idoso. Nessa perspectiva, tal estudo possibilitou, portanto, "propiciar a nossos alunos práticas discursivas pedagógicas em tarefas educacionais multissemióticas significativas, para substituir tarefas com o uso somente do quadro de giz ou de cópia de exercícios gramaticais descontextualizados" (HEBERLE, 2012, p. 101).

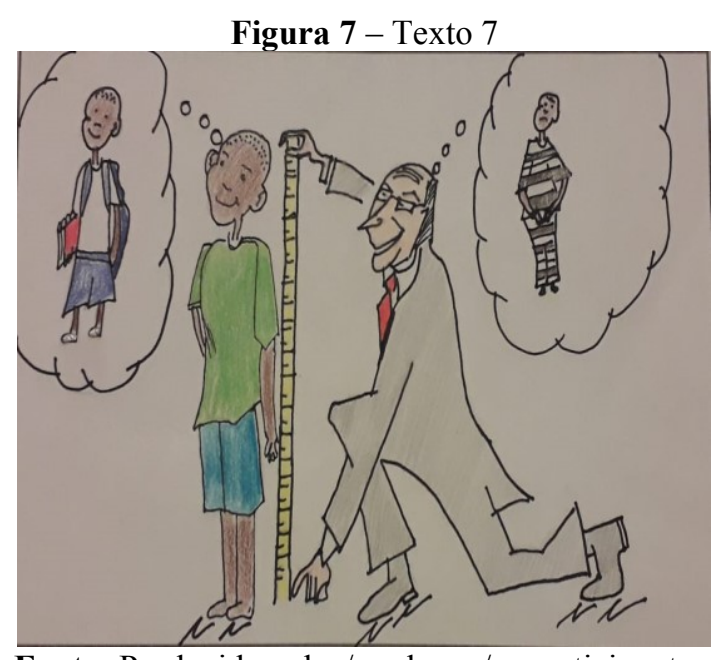

Fonte: Produzido pelos/as alunos/as participantes.

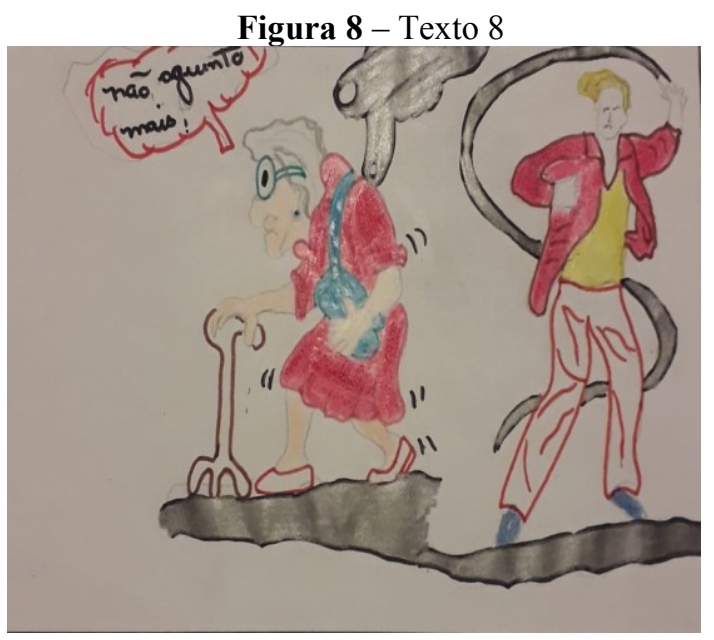

Fonte: Produzido pelos/as alunos/as participantes.

Durante as oficinas, prezamos pela perspectiva do/a aluno/a protagonista em seu percurso de aprendizagem e agente de seu próprio dizer e fazer. Nesse contexto, as produções autorais em relação ao preconceito racial destacam a "exclusão de significados que causem sofrimento humano ou significados que façam mal aos outros" (MOITA LOPES, 2006, p. 103). Além disso, os/as alunos/as foram unânimes em apontar para um "silenciamento do sujeito idoso", corroborando a ideia de Andrade (2014, p. 149).

Com base em um olhar interativo e a partir da ideia de que "imagens no contexto das instituições sociais [...] regulam o que pode ser dito [...], como deveria ser dito, e como deveria ser interpretado" (KRESS; VAN LEEUWEN, 2006, p. 114, tradução nossa), as produções analisadas, acima, são exemplos de que se torna improvável a interpretação por meio apenas da forma escrita do texto. Nessa perspectiva, dois recursos utilizados pelos/as produtores/as das charges chamam nossa atenção: em ambas, foi escolhido o contato por oferta, através do qual os participantes representados são oferecidos ao observador como um componente de informação ou de contemplação, reforçando a ideia de desaprovação da situação exposta; outro ponto relevante diz respeito à distância social apresentada nas imagens, através da qual buscase uma representação de todo o corpo dos participantes (plano aberto), criando maior visibilidade para a grave situação sendo representada e possibilitando, assim esperamos, uma maior tomada de consciência sobre tais condições sociais.

Por fim, convém destacar que essas novas configurações de construção do conhecimento em sala de aula, a partir de questões da contemporaneidade e de uma maior 
ênfase atribuída às discussões acerca das minorias, possibilitaram ratificar como válidas alternativas essenciais da vida social, as quais indicam um movimento de mudanças identitárias. Essas instabilidades podem ser referendadas por meio das narrativas expressas pelos/as alunos/as pesquisados/as, após as oficinas realizadas em sala de aula, tais como: "O Brasil é um país de muitas culturas, que devem ser valorizadas", além da "necessidade de ressignificação de fatos históricos", defendendo, assim, a construção de novas políticas culturais e de opiniões menos hegemônicas; "Onde há homofobia, existe falta não só de respeito, mas também de empatia e de bom senso", argumentando a favor das novas formas de compreender a vida em sociedade; ou ainda "A violência contra idoso é um ato desumano", além de o mesmo necessitar "viver num ambiente saudável que zele por sua vida", demonstrando, portanto, uma preocupação em relação ao novo panorama da vida social contemporânea, com vistas a "compreender a complexidade das questões que nos confrontam no cotidiano" (MOITA LOPES, 2006, p. 98).

\section{CONSIDERAÇÕES FINAIS}

Neste estudo, pretendemos demonstrar, primeiramente, a importância de um trabalho com a linguagem em sala de aula embasado em releituras multissemióticas da realidade, a partir de um forte apelo crítico-reflexivo. Em segundo plano, buscamos ressaltar a construção da indisciplina identitária (MOITA LOPES, 2006): o/a professor/a e o/a aluno/a com autoria em suas palavras, explorando uma proposta de convivência harmônica com a diversidade e a multiculturalidade.

Nesse contexto, as atividades lúdicas possibilitaram novas aprendizagens, reconfigurando arcaicas e preconceituosas relações discursivas durante as interações, porque "a ordem social não é somente linguagem, textualidade e semiose, mas é também corpórea, [...] marcada pelas diferenças sexuais, raciais e outras" (PENNYCOOK, 2006, p. 83).

Sendo assim, problematizar tais situações deve estar na "ordem do dia" das diversas escolas, afinal, nós, professores/as, não pretendemos, através dos diversos gêneros textuais entre os quais circulamos, potencializar o repertório cultural do/a discente? Está aí, então, uma das características basilares dos multiletramentos.

Por fim, vale ressaltar que nossa proposta de trabalho com charge possibilitou não apenas a leitura e produção de textos criativos dos/as alunos/as, mas também ampliou a capacidade sociocomunicativa dos/as mesmos/as sobre aspectos linguísticos, textuais, imagéticos, discursivos e identitários. Assim, as escolas necessitam preparar os aprendizes para as mudanças da atualidade que insistem em bater a sua porta, levando os/as alunos/as à apropriação dos multiletramentos e da multimodalidade, tanto dentro quanto fora do ambiente escolar.

\section{REFERÊNCIAS}

ANDRADE, E. R. de. Representações de idosos em livros didáticos de língua portuguesa para o ensino fundamental. In: CORACINI, M. J.; CARMAGNANI, A. M. G. (Orgs.). Mídia, exclusão e ensino: dilemas e desafios na contemporaneidade. Campinas: Pontes, 2014. p. 139-161.

BEZERRA, F. A análise crítica do discurso e os multiletramentos: o papel da linguagem no fazer docente contemporâneo. In: NÓBREGA, C.; ARCOVERDE, R.; BRANCO, S.; 
FARIAS, W. (Orgs.). Educação linguística e literária: discursos, políticas e práticas. Campina Grande: UFCG, 2016. p. 189-204.

BRASIL. Secretaria de Educação Fundamental. Parâmetros Curriculares Nacionais: terceiro e quarto ciclos: apresentação dos temas transversais. Brasília, DF: MECSEF, 1998.

FAIRCLOUGH, N.; WODAK, R. Critical Discourse Analysis. In: VAN DIJK, T. A. (Org.). Discourse as Social Interaction. Londres: Sage, 1997.

FUZER, C.; CABRAL, S. R. S. Introdução à gramática sistêmico-funcional em língua portuguesa. Campinas: Mercado de Letras, 2014.

HALLIDAY, M. A. K. An Introduction to Functional Grammar. Londres: Edward Arnold, 1994.

HEBERLE, V. Multimodalidade e multiletramento: pelo estudo da linguagem como prática social multissemiótica. In: SILVA, K. A. da; DANIEL, F. de G.; KANEKO-MARQUES, S. M.; SALOMÃO, A. C. B. (Orgs.). A formação de professores de línguas: novos olhares volume II. Campinas: Pontes, 2012. p. 83-106.

KRESS, G.; VAN LEEUWEN, T. Reading images: The Grammar of Visual Design. Londres: Routledge, 2006.

KLEIMAN, A. Agenda de pesquisa e ação em Linguística Aplicada: problematizações. In: MOITA LOPES, L. P. da (Org.). Linguística aplicada na modernidade recente: Festschrift para Antonieta Celani. São Paulo: Parábola Editorial, 2013. p. 39-58.

MEURER, J. L. Gêneros textuais na análise crítica de Fairclough. In: MEURER, J. L.; BONINI, A.; MOTTA-ROTH, D. (Orgs.). Gêneros: teorias, métodos, debates. São Paulo: Parábola Editorial, 2005. p. 81-106.

MOITA LOPES, L. P. Gênero, sexualidade, raça em contextos de letramentos escolares. In: MOITA LOPES, L. P. (Org.). Linguística aplicada na modernidade recente: Festschrift para Antonieta Celani. São Paulo: Parábola Editorial, 2013. p. 227-247.

MOITA LOPES, L. P. Linguística aplicada e vida contemporânea: problematização dos construtos que têm orientado a pesquisa. In: MOITA LOPES, L. P. (Org.). Por uma linguística aplicada indisciplinar. São Paulo: Parábola Editorial, 2006. p. 85-107.

NASCIMENTO, R.; BEZERRA, F.; HEBERLE, V. Multiletramentos: iniciação à análise de imagens. Linguagem \& Ensino, Pelotas, v. 14, n. 2, p. 529-552, 2011.

NEW LONDON GROUP. A pedagogy of multiliteracies: designing social futures. In: COPE, B.; KALANTZIS, M. (Orgs.). Multiliteracies: literacy learning and the design of social futures. Londres, Nova York: Routledge, 2000[1996]. p. 9-36.

PENNYCOOK, A. Uma linguística aplicada transgressiva. In: MOITA LOPES, L. P. (Org.). Por uma linguística aplicada indisciplinar. São Paulo: Parábola Editorial, 2006. p. 67-84. 
ROJO, R. Pedagogia dos multiletramentos: diversidade cultural e de linguagens na escola. In: ROJO, R.; MOURA, E. (Orgs.). Multiletramentos na escola. São Paulo: Parábola Editorial, 2012. p. 11-31.

SANTOS, B. de S. Do pós-modernismo ao pós-colonial. E para além de um e de outro. Coimbra: Centro de Estudos Sociais da Universidade de Coimbra, 2004. Mimeografado.

SERAFINI, F. Reading the visual: an introduction to teaching multimodal literacy. Londres: Teachers College Press, 2014.

Recebido em: 20 de março de 2020

Aceito em: 16 de julho de 2020

Publicado em Setembro de 2020 